\title{
Submicrometer Hall devices fabricated by focused electron-beam-induced deposition
}

\author{
G. Boero, ${ }^{\text {a) }}$ I. Utke, T. Bret, N. Quack, M. Todorova, S. Mouaziz, P. Kejik, J. Brugger, \\ R. S. Popovic, and P. Hoffmann \\ Swiss Federal Institute of Technology at Lausanne (EPFL), CH-1015 Lausanne, Switzerland
}

(Received 21 September 2004; accepted 1 December 2004; published online 19 January 2005)

\begin{abstract}
Hall devices having an active area of about $(500 \mathrm{~nm})^{2}$ are fabricated by focused electron-beam-induced deposition. The deposited material consists of cobalt nanoparticles in a carbonaceous matrix. The realized devices have, at room temperature, a current sensitivity of about $1 \mathrm{~V} / \mathrm{AT}$, a resistance of a few kilo-ohms, and can be biased with a maximum current of about $1 \mathrm{~mA}$. The room-temperature magnetic field resolution is about $10 \mu \mathrm{T} / \mathrm{Hz}^{1 / 2}$ at frequencies above 1 kHz. (c) 2005 American Institute of Physics. [DOI: 10.1063/1.1856134]
\end{abstract}

Magnetic sensors having submicrometer spatial resolution are key elements in several fundamental studies as well as industrial applications. ${ }^{1-4}$ Hall effect devices are emerging as one of the most suitable solutions. ${ }^{4-9}$ The ordinary Hall effect is due to the Lorentz force acting on charge carriers in metals, semi-metals, and semiconductors. ${ }^{5}$ Magnetic materials show additional "Hall phenomena" which are, generally speaking, generated by spin-orbit interactions: the so-called extraordinary ${ }^{10-16}$ and planar Hall effects. ${ }^{17-20}$

The local deposition of materials using a focused electron beam in the presence of a volatile precursor is a wellestablished technique for the maskless fabrication of submicrometer structures such as functionalized tips for scanning probe microscopy, ${ }^{21-26}$ electrodes for local conductivity measurements, ${ }^{27}$ solder bonds for carbon nanotubes studies, ${ }^{28}$ nanowires, ${ }^{29-33}$ and nanodots. ${ }^{34}$ In this letter we demonstrate the possibility to grow highly sensitive cobaltcarbon submicrometer Hall devices by means of a focused electron beam. This flexible "single-step" process represents an alternative to the conventional "multisteps" methods, which are usually based on a combination of optical (or electron beam) lithography and focused ion beam milling. The realized devices show a strong extraordinary Hall effect, whereas the ordinary and planar Hall effects (in most of the devices) are relatively small.

Figure 1 shows a schematic representation of the realized devices. The $\mathrm{SiO}_{2}$ layer (about $100 \mathrm{~nm}$ ) is obtained by dry oxidation. The electrodes are realized by lift-off using a $\mathrm{Au}(300 \mathrm{~nm}) / \mathrm{Ti}(20 \mathrm{~nm})$ layer. The $\mathrm{Co}-\mathrm{C}$ deposit is obtained by decomposing dicobalt octacarbonyl $\left[\mathrm{Co}_{2}(\mathrm{CO})_{8}\right]$ with the electron beam of a scanning electron microscope (Cambridge $\mathrm{S} 100)$. The deposition is performed at room temperature, at a chamber background pressure of about $10^{-3} \mathrm{~Pa}$. The deposited material consists essentially of cobalt nanoparticles (a few nanometers in diameter) embedded in carbonaceous matrix (for further details see Refs. 21-23). With a beam energy of $25 \mathrm{keV}$ and a beam current of about $0.5 \mathrm{nA}$, we obtain a beam diameter of about $200 \mathrm{~nm}$ at the focus. With a beam speed of $30 \mathrm{~nm} / \mathrm{s}$ (i.e., a line dose of about $10^{8}$ electrons $/ \mathrm{nm}$ ), the Gaussian-type deposit has height ranging from 50 to $100 \mathrm{~nm}$ and full width at half maximum

\footnotetext{
a) Author to whom correspondence should be addressed; electronic mail:
} giovanni.boero@epfl.ch
(FWHM) from 300 to $600 \mathrm{~nm}$. This corresponds approximately to one atom in the deposit every 100 electrons in the beam. The larger FWHM values in some of the devices can be attributed to insufficient charge dissipation through the isolating $\mathrm{SiO}_{2}$ films at the back side of the substrate. The local charge build-up at the place where the primary electron beam impinges the substrate enlarges the beam diameter and, consequently, increases the width (and decreases the height) of the deposit. Thicknesses and widths of the Co-C deposits are evaluated by scanning electron microscopy (SEM) (Philips XL-30) and atomic force microscopy (AFM) (NanoSurf EasyScan). Figure 2 shows SEM and AFM images of two of the realized devices. The time required for the growth of these cross-shaped devices is about $15 \mathrm{~min}$.

As clearly visible in Figs. 2(a) and 2(b), the deposition process produces a halo-deposit around the main crossshaped deposit. ${ }^{29,30}$ This large-area thin film is deposited by back-scattered electrons (BSE) and their generated secondary electrons. The lateral size of the halo corresponds to the BSE-exit-area, the diameter of which can be approximately expressed by means of the Bethe range (i.e., $7.5 \mu \mathrm{m}$ for $\mathrm{Si}$ and $0.7 \mu \mathrm{m}$ for $\mathrm{Au}$ at $25 \mathrm{keV}^{30}$ ). This explains the narrower halo formations on the Au electrodes. The number of backscattered electrons is about $15 \%$ for the $\mathrm{SiO}_{2}(100 \mathrm{~nm}) / \mathrm{Si}$ substrate. From these values, the average halo thickness on the substrate can be roughly estimated to about $2 \mathrm{~nm}$. In
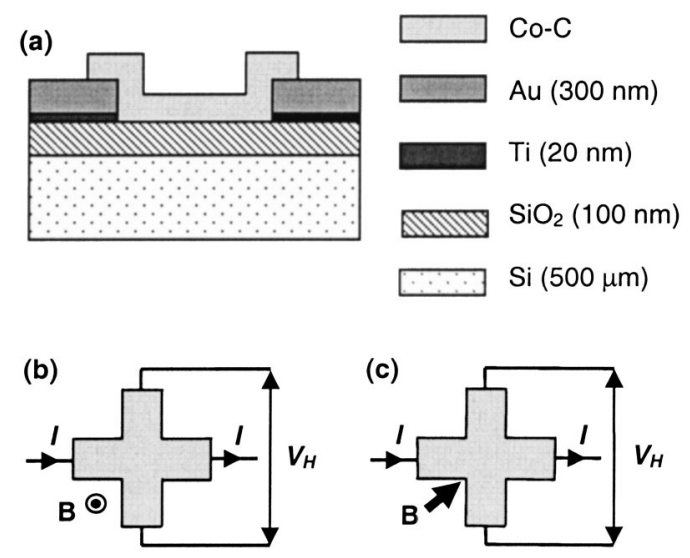

FIG. 1. (a) Schematic cross section and top view (not to scale) of the realized devices. The magnetic induction is applied: (b) out-of-plane, (c) in-plane at $45^{\circ}$. 


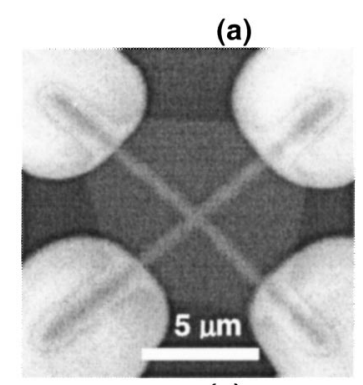

(c)

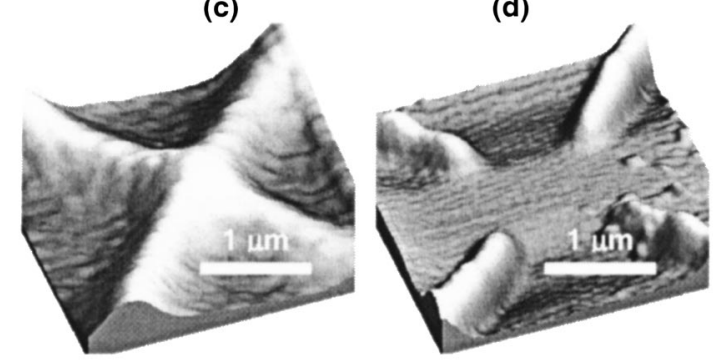

FIG. 2. SEM images: (a) complete device, (b) "open" device. AFM images (intensity scale $60 \mathrm{~nm}$ ): (c) complete device, (d) "open" device.

order to check if a significant current passes through this parasitic deposit, we fabricate some "open" devices by removing from the writing program the $1-\mu \mathrm{m}$-long central region of the two single-line scans [see Figs. 2(b) and 2(d)]. These devices have resistances higher than $1 \mathrm{M} \Omega$ (i.e., more than two orders of magnitude larger than the resistance of the complete device). Consequently, we can safely consider that the active area of the complete device is about $(500 \mathrm{~nm})^{2}$. The halo formation can be avoided using a low energy focused electron beam (e.g., at $1 \mathrm{keV}$ the diameter of the exit area on bulk $\mathrm{Si}$ is about $30 \mathrm{~nm}$ ). This experiment is straightforward in SEMs equipped with a field-emission gun but cannot be performed in our setup, where the thermoionicgun-generated beam loses dramatically its resolution at low beam energies. ${ }^{29}$

Figures 3 and 4 show the results of room temperature galvanomagnetic measurements performed on the complete device shown in Fig. 2. Each arm of the cross-shaped device has a length of about $7 \mu \mathrm{m}$, a FWHM of $500 \mathrm{~nm}$, and a thickness of about $50 \mathrm{~nm}$. Hall voltage, bias voltage $V$, and offset voltage are linearly dependent on the bias current, as expected when a good ohmic contact is established between the $\mathrm{Au} / \mathrm{Ti}$ electrodes and the $\mathrm{Co}-\mathrm{C}$ deposit. The resistance is $2 \mathrm{k} \Omega$, which corresponds to a resistivity of about 7 $\times 10^{-6} \Omega \mathrm{m}$ (i.e., two orders of magnitude larger than pure

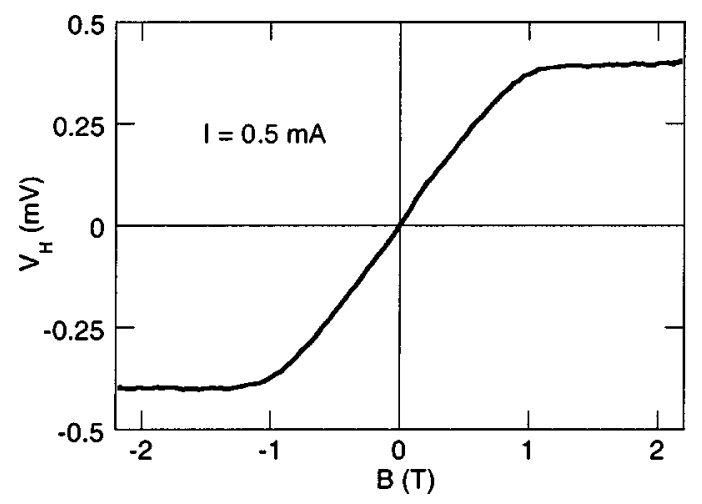
FIG. 3. Hall voltage as a function of the out-of-plane magnetic induction. Downloaded 20 Jan 2005 to 128.178.153.69. Redistribution subject

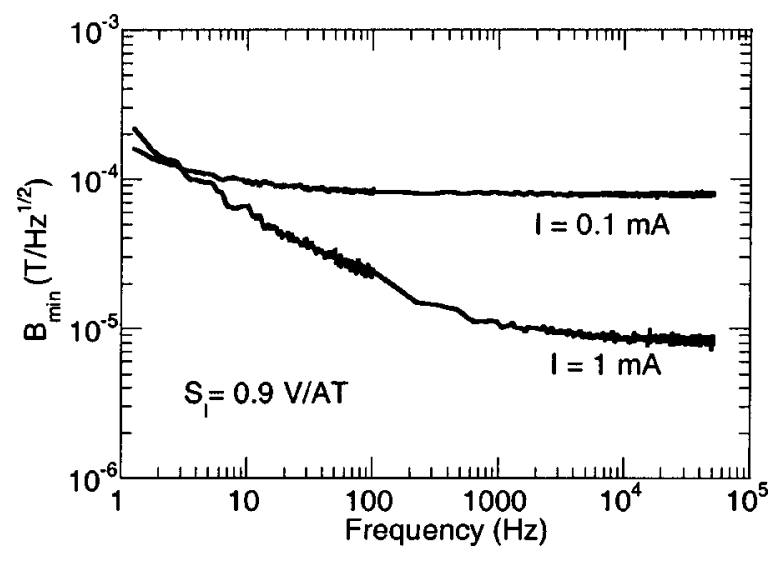

FIG. 4. Magnetic field resolution as a function of frequency.

Co). For $I=1 \mathrm{~mA}$, the offset voltage is about $8 \mathrm{mV}$ (i.e., about $0.5 \%$ of the bias voltage). Figure 3 shows the Hall voltage $V_{H}$ as a function of the externally applied magnetic induction $B$ (i.e., $B=\mu_{0} H$, where $H$ is the externally applied magnetic field). The magnetic induction is applied "out-ofplane" as shown in Fig. 1(b). The current sensitivity $S_{I}$ is about $0.9 \mathrm{~V} / \mathrm{AT}$ in the linear region (i.e., below $1 \mathrm{~T}$ ). Since the device thickness is about $50 \mathrm{~nm}$, this corresponds to a Hall coefficient $R_{H}$ of about $5 \times 10^{-8} \Omega \mathrm{m} / \mathrm{T}$ (similar to that reported for $\mathrm{Fe}-\mathrm{Pt}, \mathrm{Fe}-\mathrm{Si}, \mathrm{Ni}$, and $\mathrm{LaBaMnO}_{3}$ thin films, ${ }^{10-15}$ and $\mathrm{Fe}-\mathrm{Cr}$ multilayers ${ }^{16}$ ). The resistance between the bias current contacts varies by less than $0.5 \%$ from 0 to $2.2 \mathrm{~T}$. At magnetic inductions higher than $1 \mathrm{~T}$, the Hall voltage saturates (above $1 \mathrm{~T}$ the Hall voltage varies by only a few microvolts). This means that in the deposited material the extraordinary Hall effect largely dominates the ordinary Hall effect. The absence of a significant hysteresis in the $V_{H}-B$ curve seems to indicate that the remanent magnetization is small. This should allow one to use these devices for "weakly invasive" quantitative magnetic imaging at low magnetic fields. However, more detailed investigations are required to fully elucidate the magnetic properties of the Co-C nanowire deposit.

For practical uses as magnetic sensor, one of the most important characteristics is the magnetic field resolution. We can define the magnetic field resolution (in $\mathrm{T} / \mathrm{Hz}^{1 / 2}$ ) as $B_{\min }=N / S_{\mathrm{I}} I$, where $N$ is the noise voltage spectral density measured at the Hall voltage contacts (in $\mathrm{V} / \mathrm{Hz}^{1 / 2}$ ). Figure 4 shows the measured magnetic field resolution as a function of frequency for bias currents of 0.1 and $1 \mathrm{~mA}$. At frequencies above $1 \mathrm{kHz}$ we have $B_{\min } \sim 10 \mu \mathrm{T} / \mathrm{Hz}^{1 / 2}$ for $I=1 \mathrm{~mA}$, which corresponds approximately to the thermal noise of the resistance between the Hall voltage contacts $\left(6 \mathrm{nV} / \mathrm{Hz}^{1 / 2}\right.$ for the $2 \mathrm{k} \Omega$ tested device). At frequencies below $1 \mathrm{kHz}$, the noise grows approximately as $1 / f^{1 / 2}$, as expected for a $1 / f$ noise. At $1 \mathrm{~Hz}$, the magnetic field resolution is about $200 \mu \mathrm{T} / \mathrm{Hz}^{1 / 2}$. The achieved "high-frequency" magnetic field resolution represents one of the best results for magnetic sensors having a spatial resolution better than $1 \mu \mathrm{m}$ operating at room temperature. We are currently investigating the possibility to efficiently suppress the low-frequency noise by spinning current techniques. ${ }^{35}$

In a series of fifteen devices like that in Fig. 2, the current sensitivity varies from 0.8 to $1.2 \mathrm{~V} / \mathrm{AT}$, the resistance from 1.5 to $5 \mathrm{k} \Omega$, and the maximum bias current from 0.5 to $1 \mathrm{~mA}$ (at higher currents, the devices break down ei0.5 to $1 \mathrm{~mA}$ (at higher currents, the devices break down ei-
to AlP license or copyright, see http://apl.aip.org/apl/copyright.jsp 


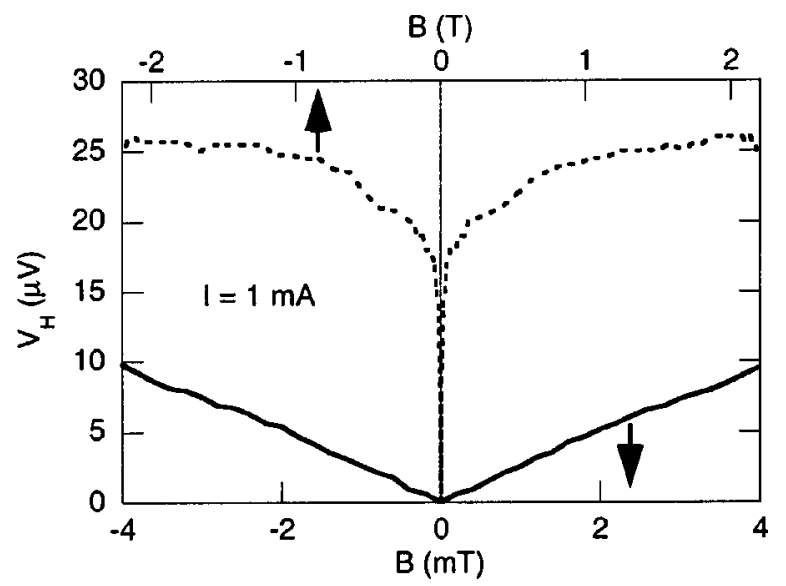

FIG. 5. Hall voltage as a function of the in-plane magnetic induction. Only a few devices show this behavior.

ther at the center of the cross or at the Au/Ti contacts). These differences could be explained by slight variations of the dimensions and nanostructure of the nanowires induced by the above-mentioned charge effects. When the magnetic field is applied in the sensor plane [see Fig. 1(b)], most of the devices show a very small planar Hall effect (i.e., in-plane current sensitivities below $0.1 \mathrm{~V} / \mathrm{AT}$ ). However, three of them show in-plane current sensitivities as large as $3 \mathrm{~V} / \mathrm{AT}$ in the linear region below $10 \mathrm{mT}$ (see Fig. 5). Presently, we do not have any convincing explanation for the large differences in the measured in-plane current sensitivities.

The magnetic and spatial resolution of focused electronbeam-induced deposition Hall devices can probably be significantly improved by a careful optimization of deposition parameters such as precursor, beam current, beam energy, beam size, beam speed, temperature, and substrate. State-ofthe-art scanning electron microscopes should allow the fabrication of devices of dimensions down to $10 \mathrm{~nm}^{32-34}$ The possibility to grow truly three-dimensional devices of nanometric dimensions, on planar substrate as well as cantilevers tips, might represent an advantage with respect to conventional "two-dimensional" structuring technologies. Applications as probes for scanning magnetic microscopy with submicrometer spatial resolution might become possible.

This work has been supported by the Top Nano 21 program of the Swiss Innovation Promotion Agency (KTI/CTI).

${ }^{1}$ S. J. Bending, Adv. Phys. 48, 449 (1999).

${ }^{2}$ M. R. Freeman and B. C. Choi, Science 294, 1484 (2001).
${ }^{3}$ S. A. Solin, Sci. Am. 291, 45 (2004).

${ }^{4}$ G. Boero, M. Demierre, P. A. Besse, and R. S. Popovic, Sens. Actuators, A 106, 314 (2003).

${ }^{5}$ R. S. Popovic, Hall Effect Devices, 2nd ed. (IOP, Bristol, 2004).

${ }^{6}$ A. J. Brook, S. J. Bending, J. Pinto, A. Oral, D. Ritchie, H. Beere, M. Henini, and A. Springthorpe, Appl. Phys. Lett. 82, 3538 (2003).

${ }^{7}$ A. Sandhu, H. Masuda, H. Senoguchi, and K. Togawa, Nanotechnology 15, S410 (2004).

${ }^{8}$ A. Sandhu, A. Okamoto, I. Shibasaki, and A. Oral, Microelectron. Eng. 73-74, 524 (2004).

${ }^{9}$ A. Sandhu, K. Kurosawa, M. Dede, and A. Oral, Jpn. J. Appl. Phys., Part 1 43, 777 (2004).

${ }^{10}$ E. M. Pugh and N. Rostoker, Rev. Mod. Phys. 25, 151 (1953).

${ }^{11}$ L. Berger and G. Bergmann, in The Hall Effects and its Applications, edited by C. L. Chien and C. R. Westgate (Plenum, New York, 1980).

${ }^{12}$ M. Zeise and C. Srinitiwarawong, Europhys. Lett. 45, 256 (1999).

${ }^{13}$ M. Watanabe and T. Masumoto, Thin Solid Films 405, 92 (2002).

${ }^{14}$ A. Gerber, A. Milner, M. Karpovsky, B. Lemke, H.-U. Habermeier, J. Tuaillon-Combes, N. Négrier, O. Boisron, P. Mélinon, and A. Perez, J. Magn. Magn. Mater. 242-245, 90 (2002).

${ }^{15}$ G. X. Miao and G. Xiao, Appl. Phys. Lett. 85, 73 (2004).

${ }^{16}$ P. Khatua, A. K. Majumdar, A. F. Hebard, and D. Temple, Phys. Rev. B 68, 144405 (2003).

${ }^{17}$ C. Goldberg and R. E. Davis, Phys. Rev. 94, 1121 (1954).

${ }^{18}$ L. Ejsing, M. F. Hansen, A. K. Menon, H. A. Ferreira, D. L. Graham, and P. P. Freitas, Appl. Phys. Lett. 84, 4729 (2004).

${ }^{19}$ Y. Bason, L. Klein, J.-B. Yau, X. Hong, and C. H. Ahn, Appl. Phys. Lett. 84, 2593 (2004).

${ }^{20}$ H. X. Tang, R. K. Kawakami, D. D. Awschalom, and M. L. Roukes, Phys. Rev. Lett. 90, 107201 (2003).

${ }^{21}$ I. Utke, P. Hoffmann, R. Berger, and L. Scandella, Appl. Phys. Lett. 80, 4792 (2002).

${ }^{22}$ I. Utke, T. Bret, D. Laub, Ph. Buffat, L. Scandella, and P. Hoffmann, Microelectron. Eng. 73-74, 553 (2004).

${ }^{23}$ Y. M. Lau, P. C. Chee, J. T. L. Thong, and V. Ng, J. Vac. Sci. Technol. A 20, 1295 (2002).

${ }^{24}$ K. I. Schiffmann, Nanotechnology 4, 163 (1993).

${ }^{25}$ M. R. Koblinshka and U. Hartmann, Ultramicroscopy 97, 103 (2003).

${ }^{26}$ M. Wendel, H. Lorenz, and J. P. Kotthaus, Appl. Phys. Lett. 67, 3732 (1995).

${ }^{27}$ P. Bøggild, T. M. Hansen, O. Kuhn, F. Grey, T. Junno, and L. Montelius, Rev. Sci. Instrum. 71, 2781 (2000).

${ }^{28}$ D. N. Madsen, K. Mølhave, R. Mateiu, A. M. Rasmussen, M. Brorson, C. J. H. Jacobsen, and P. Bøggild, Nano Lett. 3, 47 (2003).

${ }^{29}$ P. Hoffmann, I. Utke, F. Cicoira, B. Dwir, K. Leifer, E. Kapon, and P. Doppelt, Mater. Res. Soc. Symp. Proc. 624, 171 (2000).

${ }^{30}$ L. Reimer, in Scanning Electron Microscopy, Springer Series in Optical Sciences 45 (Springer, Berlin, 1985).

${ }^{31}$ V. Gopal, E. A. Stach, V. R. Radmilovic, and I. A. Mowat, Appl. Phys. Lett. 85, 49 (2004).

${ }^{32}$ Z. Liu, K. Mitsuishi, and K. Furuya, Nanotechnology 15, S414 (2004).

${ }^{33}$ N. Silvis-Cividjian, C. W. Hagen, P. Kruit, M. A. J. v. d. Stam, and H. B. Groen, Appl. Phys. Lett. 82, 3514 (2003).

${ }^{34}$ K. Mitsuishi, M. Shimojo, M. Han, and K. Furuya, Appl. Phys. Lett. 83, 2064 (2003).

${ }^{35}$ P. J. A. Munter, Sens. Actuators, A 21-23, 743 (1990). 